\title{
Fenton reaction-based colorimetric immunoassay for sensitive detection of brevetoxin B
}

\author{
Wenqiang Lai a, Qiaohua Wei ${ }^{a, *}$, Junyang Zhuang a, Minghua Lu ${ }^{b, *}$, Dianping Tanga \\ a State Key Laboratory of Photocatalysis on Energy and Environment, Key Laboratory of Analysis and \\ Detection for Food Safety (Fujian Province \& MOE), Institute of Nanomedicine and Nanobiosensing, \\ Department of Chemistry, Fuzhou University, Fuzhou 350108, P.R. China \\ ${ }^{\mathrm{b}}$ Institute of Environmental and Analytical Science, School of Chemistry and Chemical Engineering, Henan \\ University, Kaifeng 475004, Henan, P.R. China
}

\begin{abstract}
We designed a new colorimetric immunoassay for sensitive monitoring of brevetoxin B (BTB) using enzyme-controlled Fenton reaction with a high-resolution 3,3',5,5'-tetramethylbenzidine (TMB)-based visual colored system. Upon addition of hydrogen peroxide $\left(\mathrm{H}_{2} \mathrm{O}_{2}\right)$, the equivalent iron(II) could be first converted into iron(III) and free hydroxyl radical $(\bullet \mathrm{OH})$ via the classical Fenton reaction. Then the as-produced iron(III) and $\bullet \mathrm{OH}$ could cause a perceptible change from colorless to blue with the increasing $\mathrm{H}_{2} \mathrm{O}_{2}$ concentration in the presence of TMB. Based on Fenton reaction-triggered visual colored system, a novel competitive-type colorimetric enzyme immunoassay was developed for the quantitative screening of target BTB on the bovine serum albumin-BTB-modified magnetic bead using glucose oxidase/anti-BTB antibody-labeled gold nanoparticle as the signal-transduction tag. Upon target BTB introduction, the analyte competed with the conjugated BTB on the magnetic bead for anti-BTB antibody on gold nanoparticle. The carried glucose oxidase with the gold nanoparticle could implement the oxidation of glucose to produce $\mathrm{H}_{2} \mathrm{O}_{2}$, and the generated $\mathrm{H}_{2} \mathrm{O}_{2}$ promoted the above-mentioned Fenton reaction for color development. Under the optimal conditions, the absorbance decreased with the increasing target BTB in the range from 0.1 to $150 \mathrm{ng} \mathrm{kg}^{-1}$ with a low detection limit (LOD) of $0.076 \mathrm{ng} \mathrm{kg}^{-1}$. The LOD was 500-fold lower than that of commercialized Abraxis BTB ELISA kit. Non-specific adsorption was not observed. The precision, reproducibility and specificity were acceptable.
\end{abstract}

\footnotetext{
${ }^{*}$ Corresponding author. Fax: +865912286 6135.

E-mail address: dianping.tang@fzu.edu.cn.
} 
Finally, the method accuracy was also validated for monitoring spiked seafood samples, giving results well matched with the referenced brevetoxin ELISA kit.

KEYWORDS: Fenton reaction; colorimetric immunoassay; brevetoxin B; magnetic beads; gold nanoparticles

\section{Introduction}

Recently, a lot of attention has been focused on the detection of small molecules (e.g., marine toxins and mycotoxins) based on different signal-generation principles, e.g., fluorescence assay, radioimmunoassay, electrochemical method, enzyme-linked immunosorbent immunoassay and chemiluminescence immunoassay ( $\mathrm{Li}$ et al., 2011; Li et al., 2014; Korde et al., 2003; Garden et al., 2001; Lin et al., 2015a; Wang et al., 2013). Among these methods, colorimetric immunoassay is usually employed as an optional scheme for assay development because of its simplicity, general applicability and high-speed operation (Xianyu et al., 2014; Zhou et al., 2012; Gao et al., 2014a; Zhang et al., 2011; Zhou et al., 2014). Despite some advances in this field, it would be advantageous to explore more flexible, yet highly sensitive, quantitative, and easy-to-use methods to meet the demand of expectations in future point-of-care testing.

Typically, hydrogen peroxide $\left(\mathrm{H}_{2} \mathrm{O}_{2}\right.$, a kind of strong oxidizer) is applied in the colorimetric assays since it can be utilized for catalytic oxidation and coloration of chromogenic agents (e.g., 3,3',5,5'-tetramethylbenzidine, TMB) with the aid of horseradish peroxidase (HRP) through the following reaction: $\mathrm{H}_{2} \mathrm{O}_{2}+\mathrm{TMB}_{(\mathrm{R})}$ (colorless) $\rightarrow 2 \mathrm{H}_{2} \mathrm{O}+\mathrm{TMB}_{(\mathrm{O})}$ (blue) (Lu et al., 2015; Liu et al., 2012a; Wan et al., 2012; Jv et al., 2010). In this case, one molecular $\mathrm{H}_{2} \mathrm{O}_{2}$ can only produce one molecular $\mathrm{TMB}_{(\mathrm{O})}\left(\right.$ i.e., $\left.\mathrm{H}_{2} \mathrm{O}_{2}: \mathrm{TMB}_{(\mathrm{O})}=1: 1\right)$. So, the detectable sensitivity by traditional $\mathrm{H}_{2} \mathrm{O}_{2}$-TMB system is always limited. To tackle this shortcoming, our motivation in this work is to explore a new signal amplification strategy by changing the molar ratio of $\mathrm{TMB}(\mathrm{O})$ and $\mathrm{H}_{2} \mathrm{O}_{2}$. Inspiringly, the emergence of Fenton reaction opens a new horizon for development of advanced colorimetric detection methods (Sedlak et al., 1991; Walling et al., 1975; Nguyen et al., 2015; Walling et al., 1982; Zazo et al., 2005). In 1894, the chemist (Fenton) innovatively found that $\mathrm{H}_{2} \mathrm{O}_{2}$ and iron(II) could be used to oxidize contaminants or waste waters, called Fenton's reagent, as follows: $\mathrm{H}_{2} \mathrm{O}_{2}+\mathrm{Fe}^{2+} \rightarrow \mathrm{Fe}^{3+}+\mathrm{OH}^{-}+\cdot \mathrm{OH}$. During this process, iron(II) is oxidized by $\mathrm{H}_{2} \mathrm{O}_{2}$ to iron(III), forming a hydroxyl radical and a hydroxide ion (Yu et al., 2014; Lyu et al., 2015). 
The generated $\bullet \mathrm{OH}$ can oxidize TMB to produce a blue product. As is well known, the oxidation potential of hydroxyl radical reaches up to $2.73 \mathrm{~V}$, which is much stronger than that of iron(III) $(0.771 \mathrm{~V})$ or silver(I) $(0.799 \mathrm{~V})$ in $\mathrm{pH} 4.0$ solution [Note: Iron(III) and silver(I) can directly oxidize TMB (González-Fuenzalida et al., 2013; Liu et al., 2012b)]. In this regard, the produced iron(III) and $\bullet \mathrm{OH}$ through Fenton reaction can simultaneously oxidize TMB to produce visual colored change (i.e., $\mathrm{H}_{2} \mathrm{O}_{2}: \mathrm{TMB}_{(\mathrm{O})}=1: 2$ ). We expect that it would be preferable for the in situ amplified signal if such a system is applied for visual detection scheme. To the best of our knowledge, there is no report focusing on Fenton reaction-based colorimetric immunoassay for the signal amplification. More significantly, $\mathrm{H}_{2} \mathrm{O}_{2}$ can be generated by glucose oxidase ( $\mathrm{GO} x$ ) toward the oxidation of glucose (Lai et al., 2014). Based on this concept, the Fenton reaction-based TMB system can be not only used for quantitative monitoring of GOx activity, but also utilized for the development of colorimetric immunoassay by GOx-labeled detection antibody.

Brevetoxin B (BTB, as a suite of cyclic polyether compounds produced naturally by a species of dinoflagellate known as Karenia brevis) can cause intoxication and even mortality through consumption of contaminated shellfish (Zhang et al., 2012). Herein, we use BTB as a model analyte for the development of Fenton reaction-based colorimetric immunoassay with the aid of GOx. The assay is carried out on magnetic immunosensing probes using nanogold-labeled GO $x$ and detection antibody with a competitive-type immunoassay format. In the presence of target BTB, the carried GOx accompanying gold nanoparticles initially oxidizes glucose to gluconic acid and $\mathrm{H}_{2} \mathrm{O}_{2}$, and the latter can oxidize iron(II) into iron(III) with the formation of $\bullet \mathrm{OH}$. The generated iron(III) and $\bullet \mathrm{OH}$ can catalyze the oxidation of TMB for visual color development. By monitoring the change in the color/absorbance, we can qualitatively/quantitatively determine the concentration of target BTB in the sample.

\section{Experimental}

\subsection{Material and chemicals}

Monoclonal mouse anti-brevetoxin antibody $(\mathrm{mAb})$ and brevetoxin B-bovine serum albumin (BTB-BSA) conjugate were gifted from College of Chemistry of Soochow University (Suzhou, China). The standards including brevetoxins A, B, and C, okadaic acid, saxitoxin acetate and 
dinophysistoxin-1,6 were purchased from Express Technol. Inc. (Beijing, China). GOx and $\mathrm{HAuCl}_{4} 4 \mathrm{H}_{2} \mathrm{O}$ were acquired from Sigma-Aldrich. 3,3',5,5'-Tetramethylbenzidine (TMB) and BSA were achieved from Sinopharm Chem. Re. Inc. (Shanghai, China). Glucose, $\mathrm{Fe}_{2}\left(\mathrm{SO}_{4}\right)_{3}$ and $\mathrm{FeSO}_{4} 7 \mathrm{H}_{2} \mathrm{O}$ were obtained from Fuchen Chemicals (Tianjin, China). Brevetoxin B ELISA kit was purchased from Abraxis LLC (Warminster, PA, USA). High-binding polystyrene 96-well microplates were obtained from Greiner Bio-One (Frickenhausen, Germany, cat\#: 655061). All other reagents were used as received without further purification. All water used in this work was of Milli-Q ultrapure grade (EMD Millipore). For pH 9.6 carbonate buffer, $\mathrm{Na}_{2} \mathrm{CO}_{3}(1.59 \mathrm{~g})$ and $\mathrm{NaHCO}_{3}(2.93 \mathrm{~g})$ were dissolved in $1000 \mathrm{~mL}$ distilled water. Tris- $\mathrm{HCl}$ buffers including $\mathrm{pH}$ $4.0(0.05 \mathrm{M})$ and $\mathrm{pH} 7.0(0.5 \mathrm{mM})$ were adjusted by adding $0.1 \mathrm{M} \mathrm{HCl}$. Phosphate buffer saline (PBS, pH 7.4) was prepared by using $2.9 \mathrm{~g} \mathrm{Na}_{2} \mathrm{HPO}_{4}, 0.24 \mathrm{~g} \mathrm{KH}_{2} \mathrm{PO}_{4}, 0.2 \mathrm{~g} \mathrm{KCl}$ and $8.0 \mathrm{~g} \mathrm{NaCl}$ in $1000 \mathrm{~mL}$ distilled water. The washing and blocking buffers were obtained by adding $0.05 \%$ Tween $20(\mathrm{v} / \mathrm{v})$ and $0.1 \mathrm{wt} \%$ BSA in PBS, respectively.

\subsection{Bioconjugation of magnetic bead with BTB-BSA (BTB-MB)}

BTB-BSA-functionalized magnetic bead (denoted as BTB-MB) was prepared similar to our previous report (Lai et al., 2015). Initially, $50 \mathrm{mg}$ of magnetic beads (100 $\mathrm{nm}$ in diameter) (Chemical GmbH, Berlin, Germany) was dissolved into $1.0 \mathrm{~mL}$ of anhydrous ethanol. Then, 3-aminopropyltriethoxysilane $(30 \mu \mathrm{L}, 98 \mathrm{wt} \%)$ was added into the suspension and reacted for 6 $\mathrm{h}$ at room temperature (RT) under gentle shaking. Following that, the aminated magnetic beads, collected by an external magnet, were suspended in $1.0 \mathrm{~mL}$ of $15 \mathrm{wt} \%$ glutaraldehyde (excess) and reacted for another $6 \mathrm{~h}$. Afterwards, the precipitate obtained by magnetic separation was placed into BTB-BSA carbonate buffer $(1.0 \mathrm{~mL}, 100 \mu \mathrm{g} \mathrm{mL}-1, \mathrm{pH} 9.6)$ and incubated for $6 \mathrm{~h}$ under the same conditions. The unconjugated BTB-BSA molecules were removed by magnetic separation. Finally, BTB-MB precipitates were dispersed in $1.0 \mathrm{~mL}$ of $\mathrm{pH} 7.4 \mathrm{PBS}$ containing $1.0 \mathrm{wt} \% \mathrm{BSA}$ and $0.1 \mathrm{wt} \%$ sodium azide for further use (storage at $4{ }^{\circ} \mathrm{C}$ when not use).

\subsection{Bioconjugation of gold nanoparticle with GOx and $m A b$ antibody (GOx-AuNP-mAb)}

Bioconjugation of gold nanoparticles (15 nm in diameter, Sigma-Aldrich) with GOx and mAb antibody (denoted as GOx-AuNP-mAb) was prepared referring to our previous works (Lai et al., 
2015). Briefly, mAb (1.0 $\left.\mu \mathrm{L}, 1.0 \mathrm{mg} \mathrm{mL}^{-1}\right)$ and GOx $\left(10 \mu \mathrm{L}, 1.0 \mathrm{mg} \mathrm{mL}^{-1}\right)$ were initially injected into $1.0 \mathrm{~mL}$ of $\mathrm{pH} 9.0$ gold colloids $(0.24 \mu \mathrm{M})$ and incubated for $12 \mathrm{~h}$ at $4{ }^{\circ} \mathrm{C}$ with slight shaking. Thereafter, the resulting suspension was centrifuged at $14,000 \mathrm{~g}$ for $20 \mathrm{~min}$ at $4{ }^{\circ} \mathrm{C}$. The obtained precipitate (i.e., GOx-AuNP-mAb) was dispersed in $1.0 \mathrm{~mL}$ of $\mathrm{pH} 7.4 \mathrm{PBS}$ containing $1.0 \mathrm{wt} \%$ BSA and $0.1 \mathrm{wt} \%$ sodium azide, and stored at $4{ }^{\circ} \mathrm{C}$ for further use.

\subsection{Monitoring of GOx activity by Fenton reaction}

Scheme 1 gives the detection principle of GOx bioactivity based on the Fenton reaction. The assay was carried out as follows: (i) $10 \mu \mathrm{L}$ of GOx with different enzymatic activities (from 0 to $2000 \mathrm{mU} \mathrm{mL}^{-1}$ ) was added into $50 \mu \mathrm{L}$ Tris- $\mathrm{HCl}$ buffer (pH 7.0) containing $4.0 \mathrm{mM}$ glucose and incubated for $30 \mathrm{~min}$ at $37^{\circ} \mathrm{C}$; (ii) $10 \mu \mathrm{L}$ of $10 \mathrm{mM} \mathrm{HCl}$ and $50 \mu \mathrm{L} 8.0 \mathrm{mM}$ of iron(II) solution were injected into the resulting solution and reacted for $15 \mathrm{~min}$ at RT; and (iii) $100 \mu \mathrm{L}$ of 1.0 mM TMB substrate solution (ethanol : buffer = $1: 9$ ) in $\mathrm{pH} 4.0$ Tris-HCl buffer was injected and incubated for $30 \mathrm{~min}$ at RT. The resultant mixture was monitored on a microplate reader (Tecan Infinite 200 PRO, TECAN, Switzerland), and the absorbance was recorded at $\lambda=652 \mathrm{~nm}$.

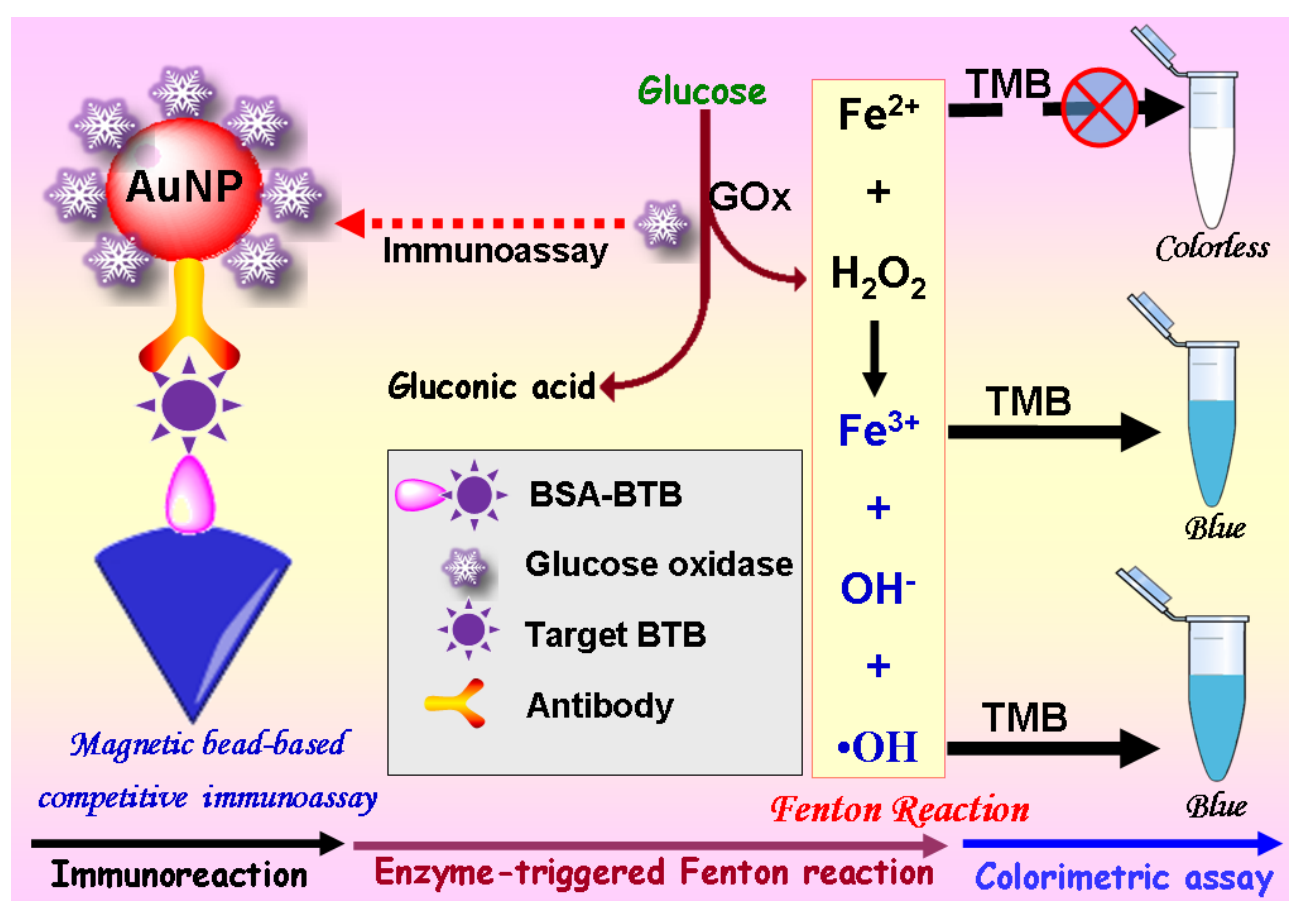

Scheme 1. Schematic illustration of Fenton reaction-based colorimetric immunoassay for target BTB by using GO $x$-AuNP-mAb as the signal-transduction tag on BTB-BSA-conjugated magnetic bead.

\subsection{Fenton reaction-based colorimetric immunoassay for target BTB}


Scheme 1 displays the detection principle of Fenton reaction-based colorimetric immunoassay toward target BTB. Initially, $25 \mu \mathrm{L}$ of BTB standard/sample and $50 \mu \mathrm{L}$ of GOx-AuNP-mAb suspension $\left(\mathrm{C}_{[\mathrm{Au}]} \approx 0.24 \mu \mathrm{M}\right)$ were added in sequence to $25 \mu \mathrm{L}$ of BTB-MB suspension (6 mg $\mathrm{mL}^{-1}$ ) in a $200-\mu \mathrm{L}$ PCR tube, and incubated for $60 \mathrm{~min}$ at $37^{\circ} \mathrm{C}$ (adequately reaction) with gentle shaking. After that, the resulting suspension was collected by magnetic separation and washed with the washing buffer. $50 \mu \mathrm{L}$ of $4 \mathrm{mM}$ glucose ( $\mathrm{pH} 7.0$ Tris- $\mathrm{HCl}$ ) was added to the precipitate and incubated for $30 \mathrm{~min}$ at $37^{\circ} \mathrm{C}$. Following that, $10 \mu \mathrm{L}$ of $10 \mathrm{mM} \mathrm{HCl}$ and $50 \mu \mathrm{L}$ of $8 \mathrm{mM}$ iron(II) were injected to the mixture in turn as before. Finally, $100 \mu \mathrm{L}$ of $1.0 \mathrm{mM}$ TMB substrate solution was added and incubated for $30 \mathrm{~min}$ for color development. Meanwhile, the absorbance was registered and recorded at $\lambda=652 \mathrm{~nm}$ on a plate reader.

\subsection{Preliminary application of Fenton reaction-based portable test kit}

Initially, $20 \mathrm{mg}$ of agarose was dissolved into the boiling water $(2 \mathrm{~mL})$ with vigorous stirring. After being cooled to $40{ }^{\circ} \mathrm{C}, 200 \mu \mathrm{L}$ of iron(II) $(8 \mathrm{mM})$ and $300 \mu \mathrm{L}$ of TMB (10 mM) was added and homogeneously dispersed in the mixture. Following that, $150 \mu \mathrm{L}$ of the formed suspension was transferred to the inner cap of a $1.5-\mathrm{mL}$ centrifugal tube. Subsequently, the agarose gel was formed after being dried under the ambient temperature for $5 \mathrm{~min}$. Finally, the as-prepared test kit was stored at $4{ }^{\circ} \mathrm{C}$ before use (Note: The test kit was stable for at least two weeks).

For the preliminary application of the agarose gel test kit (Note: The immunoreaction and the colored reaction were carried out at the bottom and the inner cap of the centrifugal tube, respectively), target BTB $(25 \mu \mathrm{L})$ and $\mathrm{GO} x$-AuNP-mAb $\left(50 \mu \mathrm{L}, \mathrm{C}_{[\mathrm{Au}]} \approx 0.24 \mu \mathrm{M}\right)$ were initially added in turn to $25 \mu \mathrm{L}$ of BTB-MB $\left(6 \mathrm{mg} \mathrm{mL}^{-1}\right)$ in the centrifugal tube of an agarose gel test kit and incubated for $60 \mathrm{~min}$ at $37^{\circ} \mathrm{C}$ with gentle shaking. After that, the resulting suspension was collected by magnetic separation and washed with the washing buffer. $50 \mu \mathrm{L}$ of $4 \mathrm{mM}$ glucose ( $\mathrm{pH} 7.0$ Tris- $\mathrm{HCl}$ ) was added to the precipitate and incubated for $30 \mathrm{~min}$ at $37{ }^{\circ} \mathrm{C}$. Following that, $10 \mu \mathrm{L}$ of $10 \mathrm{mM} \mathrm{HCl}$, and $240 \mu \mathrm{L}$ Tris- $\mathrm{HCl}$ (50 mM, pH 4.0) were injected into the mixture as before. Subsequently, the cap was closed and the centrifugal tube was turned upside down to allow the infiltration of the sample solution into the agarose gel for visible color development. The color intensity (blue) of the agarose gel directly depended on the level of target BTB in the sample. 


\section{Results and discussion}

\subsection{Design of Fenton reaction-based colorimetric immunoassay}

To develop a user-friendly sensitive colorimetric immunoassay, a simple high-efficient color progression would be advantageous. In this work, BSA-BTB conjugates are covalently bound to magnetic beads via 3-aminopropyltriethoxysilane and glutaraldehyde, while GOx and antibody are labeled to gold nanoparticles by the interaction between nanogold and thiols or alkylamines of the proteins. The biofunctionalized nanoparticles were characterized and described in our previous works (Tang et al., 2010; Tang et al., 2011; Zhang et al., 2012). Methods based on peroxidase-mediated $\mathrm{H}_{2} \mathrm{O}_{2}$-TMB system have been developed in colorimetric immunoassays (Jiang et al., 2013; Gao et al., 2013), but most involve in low sensitivity or poor visible color, thus are unfavorable for routine use. As is well known, Fenton reaction can catalyze iron(II) to iron(III), as well produce free hydroxyl radical. The generated iron(III) and free hydroxyl radical can give rise to the oxidization of TMB, thereby resulting in the progression of blue color and a strong absorbance at $652 \mathrm{~nm}$. Fig. 1A shows UV-vis adsorption spectra of TMB in the presence and absence of iron(III). No characteristic absorption peaks from 300 to $800 \mathrm{~nm}$ were observed toward TMB (curve ' $a$ ') and iron(III) (curve ' $b$ ') alone, respectively. In contrast, two strong absorption peaks were simultaneously achieved after interaction of $1.0 \mathrm{mM}$ TMB with $1.0 \mathrm{mM}$ iron(III) (curve ' $c$ '), which was ascribed to the oxidation of TMB by iron(III). Moreover, the colorless TMB became blue upon addition of iron(III) (Fig. 1A, inset ' $c$ '). These results revealed that iron(III) could oxidize TMB to trigger a blue color and an absorption peak at $652 \mathrm{~nm}$.

The second concern on our design was whether iron(II) could induce the progression of the color. To verify this point, iron(III) and iron(II) alone (1.0 mM used in this case) were added into TMB solution, respectively. The resulting mixture was monitored by using UV-vis absorption spectroscopy, respectively (Fig. 1B). As seen from curve ' $b$ ', mixture of iron(II) with TMB did not cause the appearance of the characteristic peak. The results revealed that iron(II) could not oxidize TMB whereas iron(III) could oxidize TMB. So, the chemical conversion of iron(II) to iron(III) could trigger the ongoing of the colorimetric system with the colored product. 

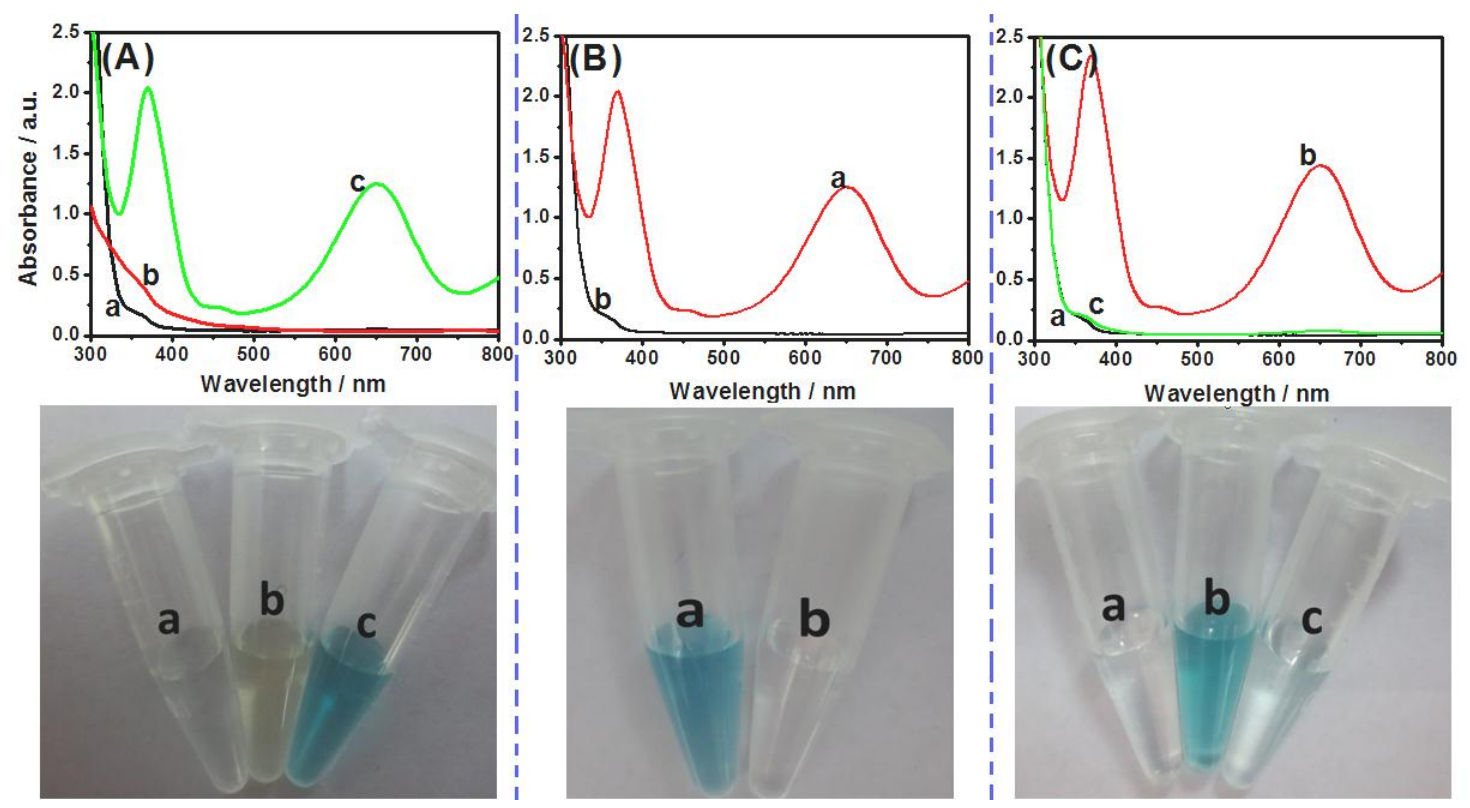

Fig. 1. (A) UV-vis absorption spectra of (a) $1.0 \mathrm{mM} \mathrm{TMB}$, (b) $1.0 \mathrm{mM}$ iron(III) and (c) $1.0 \mathrm{mM}$ iron(III) +1.0 mM TMB; (B) UV-vis absorption spectra of (a) $1.0 \mathrm{mM}$ iron(III) + $1.0 \mathrm{mM}$ TMB and (b) $8.0 \mathrm{mM}$ iron(II) + $1.0 \mathrm{mM}$ TMB; and (C) UV-vis absorption spectra of (a) $8.0 \mathrm{mM}$ iron(II) + $1.0 \mathrm{mM} \mathrm{TMB}$, (b) $1.0 \mathrm{mM} \mathrm{H}_{2} \mathrm{O}_{2}+$ $8.0 \mathrm{mM}$ iron(II) $+1.0 \mathrm{mM} \mathrm{TMB}$ and (c) $1.0 \mathrm{mM} \mathrm{H} \mathrm{H}_{2} \mathrm{O}_{2}+1.0 \mathrm{mM}$ TMB (Insets: the corresponding photographs) (Incubation time: $30 \mathrm{~min}$; Incubation temperature: $25 \pm 1.0^{\circ} \mathrm{C}$ ).

The third question arises as to whether hydrogen peroxide $\left(\mathrm{H}_{2} \mathrm{O}_{2}\right)$ could cause the chemical conversion between iron(II) and iron(III) to complement color development. To demonstrate this issue, $50 \mu \mathrm{L}$ of $1.0 \mathrm{mM} \mathrm{H}_{2} \mathrm{O}_{2}, 50 \mu \mathrm{L}$ of $8 \mathrm{mM}$ iron(II) and $100 \mu \mathrm{L}$ of $1.0 \mathrm{mM}$ TMB were utilized in this case (Fig. 1C). As shown from curve ' $b$ ' and photograph ' $b$ ', two characteristic peaks and blue color could be achieved only when $\mathrm{H}_{2} \mathrm{O}_{2}$, iron(II) and TMB were present in the solution. Significantly, the absorbance at $652 \mathrm{~nm}$ in the $\mathrm{H}_{2} \mathrm{O}_{2}$-iron(II)-TMB system (Fig. 1C, curve ' $b$ ') was much higher than that of the iron(III)-TMB system (Fig. 1A, curve ' $c$ '). The reason might be the fact that the interaction of one-molar $\mathrm{H}_{2} \mathrm{O}_{2}$ with one-molar iron(II) could produce one-molar iron(III) and one-molar $\bullet \mathrm{OH}$. The generated iron(III) and $\bullet \mathrm{OH}$ could catalyze two-molar TMB for the color development, thus resulting in the signal amplification. Theoretically, the intensity using the $\mathrm{H}_{2} \mathrm{O}_{2}$-iron(II)-TMB system should be two-fold increase relative to the iron(III)-TMB system. Maybe, the added $\mathrm{H}_{2} \mathrm{O}_{2}$ and iron(II) did not completely transform to iron(III) and $\bullet \mathrm{OH}$, thus resulting in a relatively low signal amplification.

\subsection{Control tests for Fenton reaction-based colorimetric system}


To investigate whether Fenton reaction-based colorimetric system could be really realized by $\mathrm{GO} x$-triggered $\mathrm{H}_{2} \mathrm{O}_{2}$ generation with chemical conversion of iron(II) to iron(III), several control tests were carried out under the different conditions (Fig. 2). As indicated from curve ' $a$ ', two obvious characteristic peaks at 652 and $372 \mathrm{~nm}$ were appeared upon addition of GOx into the glucose-iron(II)-TMB system. As seen from Fig. 4D, the absorbance at $652 \mathrm{~nm}$ increased with the increasing $\mathrm{GO} x$ concentration. In the absence of GOx (curve ' $b$ '), glucose (curve 'c'), iron(II) (curve ' $d$ ') or TMB (curve ' $e$ ') alone, however, no absorption peak was achieved. Moreover, the resultant solution was colorless (photographs ' $b-e$ '). The results also revealed that iron(II) could be oxidized through the oxidizing reaction of enzymatic product to oxidize TMB into TMB(ox).

Further, we also studied the dynamic response characteristics (absorbance $v s$ reaction time) of the iron(III)-TMB system (Fig. 3A). The absorbance rapidly increased with the increasing reaction time within the initial 5 minutes, and slowly tended to level off. To ensure the adequate reaction for this system, however, 30 min was used for the color development in this work.
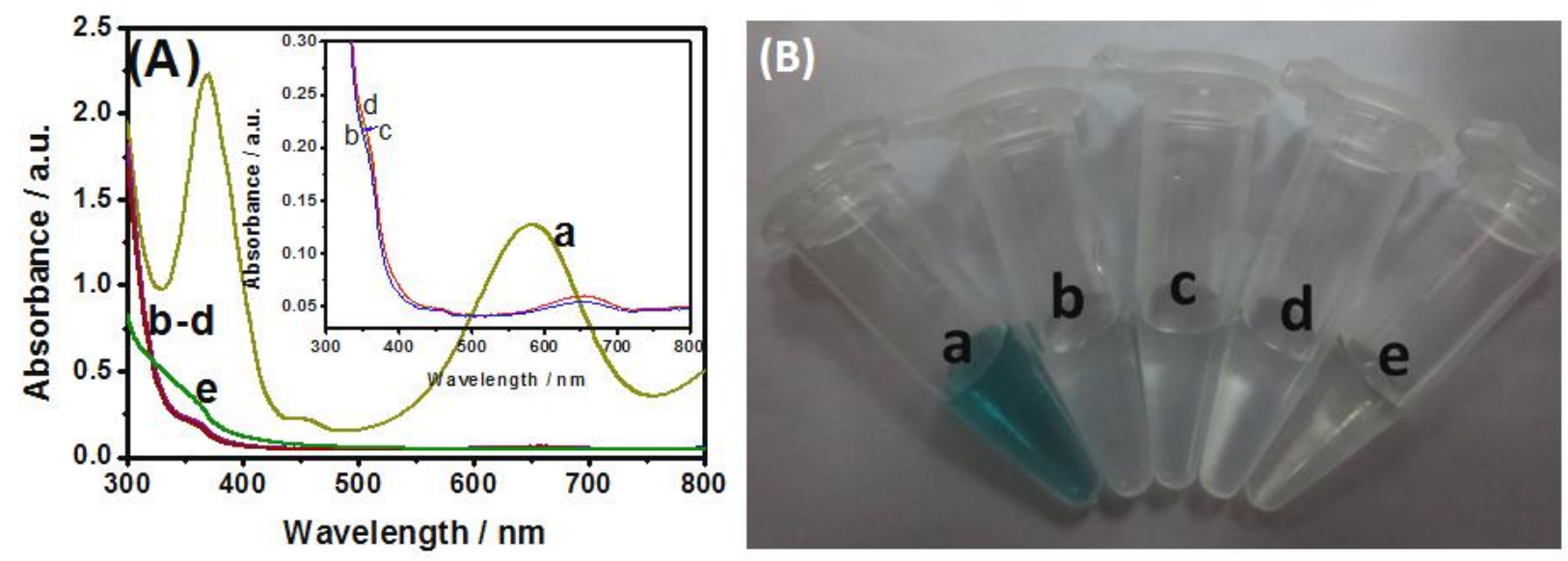

Fig. 2. (A) UV-vis absorption spectra of (a) glucose + GOx + iron(II) + TMB, (b) glucose + iron(II) + TMB, (c) GOx + iron(II) + TMB, (d) glucose + GOx + TMB and (e) glucose + GO $x+$ iron(II), respectively; and (B) the corresponding photographs for figure ' $\mathrm{A}$ '.

\subsection{Characteristics of Fenton reaction-based colorimetric assay}

To monitor the specificity of Fenton reaction-based colorimetric assay, the system was used for analysis of other possible metal ions (e.g., $\mathrm{Ag}^{+}, \mathrm{K}^{+}, \mathrm{Na}^{+}, \mathrm{Mn}^{2+}, \mathrm{Al}^{3+}, \mathrm{Ca}^{2+}, \mathrm{Cu}^{2+}, \mathrm{Zn}^{2+}, \mathrm{Co}^{2+}$, $\mathrm{Ni}^{2+}, \mathrm{Mg}^{2+}$ and $\mathrm{Fe}^{2+}$ ). As shown from Fig. 3B, a strong absorbance could be observed toward $\mathrm{Fe}^{3+}$, even if high-concentration interfering components were present. The same results could be also achieved as shown from the corresponding photographs in Fig. 3C. Although recent report 
found that $\mathrm{Ag}^{+}$could cause the visible color of TMB (Lai et al., 2015), Favorably, introduction of Tris- $\mathrm{HCl}$ in this work would mask the expected effect of $\mathrm{Ag}^{+}$due to the formation of the insoluble $\mathrm{AgCl}$. Hence, the specificity of iron(III)-TMB system was satisfactory. Meanwhile, the absorbance of iron(III)-TMB system increased with the increasing iron(III) concentration in the working range of $20-200 \mu \mathrm{M}$, and the detection limit was $\sim 15 \mu \mathrm{M}$ (Fig. 3D), indicating that the iron(III)-TMB system was feasible for quantitative monitoring of iron(III).
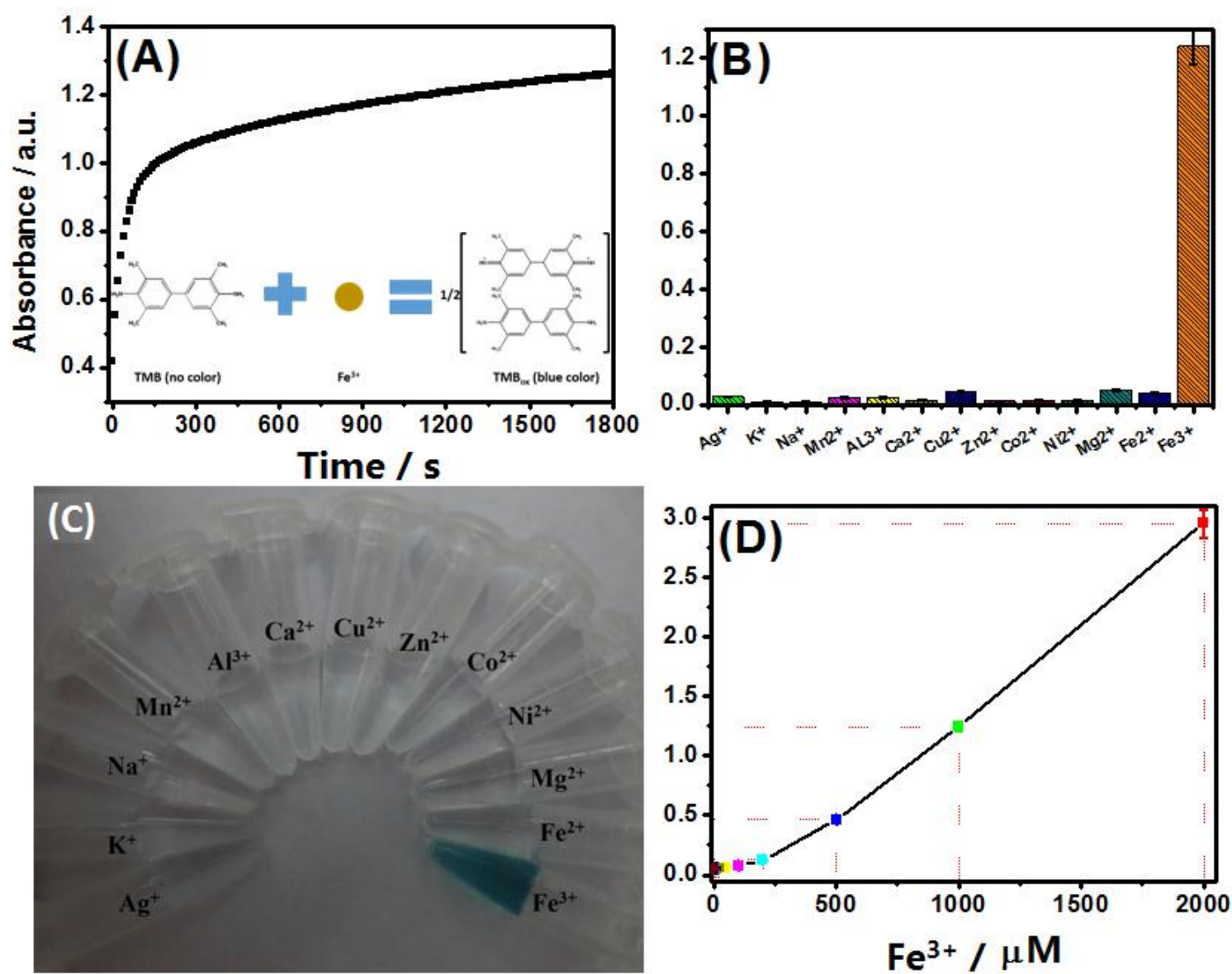

Fig. 3. (A) Effect of different reaction times between TMB and iron(III) $[1.0 \mathrm{mM}$ iron(III) used in this case $]$ on the absorbance of the iron(III)-TMB system; (B) comparison of the absorbance of TMB after interaction with different ions $\left(\mathrm{Ag}^{+}, \mathrm{K}^{+}, \mathrm{Na}^{+}, \mathrm{Mn}^{2+}, \mathrm{Al}^{3+}, \mathrm{Ca}^{2+}, \mathrm{Cu}^{2+}, \mathrm{Zn}^{2+}, \mathrm{Co}^{2+}, \mathrm{Ni}^{2+}, \mathrm{Mg}^{2+}, \mathrm{Fe}^{2+}\right.$ and $\mathrm{Fe}^{3+}, 1.0 \mathrm{mM}$ for $\mathrm{Fe}^{3+}$ vs $20 \mathrm{mM}$ for other ions); (C) the corresponding photographs for figure 'B'; and (D) calibration plots of the iron(III)-TMB system toward iron(III) standards with various concentrations.

Further, we also studied the effect of $\mathrm{H}_{2} \mathrm{O}_{2}$ level on Fenton reaction-based colorimetric assay. As shown from Fig. 4A, the absorbance initially increased rapidly with the increasing $\mathrm{H}_{2} \mathrm{O}_{2}$ concentration, and then tended to level off after $2 \mathrm{mM}$, suggesting that Fenton reaction-based TMB system could be used for the detection of $\mathrm{H}_{2} \mathrm{O}_{2}$. Logically, one puzzling question arises to 
whether the iron(II)- $\mathrm{H}_{2} \mathrm{O}_{2}$-TMB system could amplify the signal relative to the iron(III)-TMB system. To demonstrate this point, the same-concentration iron(II)/ $\mathrm{H}_{2} \mathrm{O}_{2}$ and iron(III) were used for the color development in the presence of TMB, respectively. As indicated from Fig. 4B, the absorbance of using the iron(II)- $\mathrm{H}_{2} \mathrm{O}_{2}$-TMB system was obviously higher than that of using the iron(III)-TMB system at the same concentration. The reason might be attributed to the formation of iron(III) and $\bullet \mathrm{OH}$ in iron(II)- $\mathrm{H}_{2} \mathrm{O}_{2}-\mathrm{TMB}$ system. However, we also found that the absorbance was higher than the expected two-fold for the range of $100-200 \mu \mathrm{M}$, which might be most likely as a consequence of the fact that the iron(II)- $\mathrm{H}_{2} \mathrm{O}_{2}-\mathrm{TMB}$ system was more sensitive than the iron(III)-TMB system. The low-concentration $\mathrm{H}_{2} \mathrm{O}_{2}$ could promote the progression of the iron(II)- $\mathrm{H}_{2} \mathrm{O}_{2}-\mathrm{TMB}$ system. As control test, isopropanol (scavenge $\bullet \mathrm{OH}$ ) and ascorbic acid (scavenge $\bullet \mathrm{OH}$ and $\mathrm{O}_{2} \bullet^{-}$) were injected into the solution, respectively. As shown in Fig. 4C, the absorbance of using isopropanol (column ' $b$ ') or ascorbic acid (column ' $c$ ') decreased relative to control test (column ' $a$ '). Meanwhile, the absorbance in column ' $b$ ' was about one half column ' $a$ ', while the absorbance of column ' $c$ ' was close to zero. Considering the reducibility of ascorbic acid toward TMB, we considered that the produced substance mainly derived from the $\bullet \mathrm{OH}$. These results also demonstrated that Fenton reaction could amplify the signal of the colorimetric assay.

Under optimal conditions $(10 \mathrm{mM} \mathrm{HCl}$ and $15 \mathrm{~min}$ for Fenton reaction, please see Figs. S1-2 in the Supporting Information), we investigated the GOx activity by using Fenton reaction-based colorimetric assay in the presence of glucose substrate. The assay principle was schematically illustrated in the inset of Fig. 4D. As seen from Fig. 4D, the absorbance linearly increased with the increasing GOx concentration in the range of $1.0-200 \mathrm{mU} \mathrm{mL}^{-1}$. A detection limit of 0.5 $\mathrm{mU} \mathrm{mL}^{-1} \mathrm{GO} x$ could be achieved at the 3 sblank criterion. Such a low detection limit provided a precondition for the development of high-sensitive colorimetric immunoassay. 

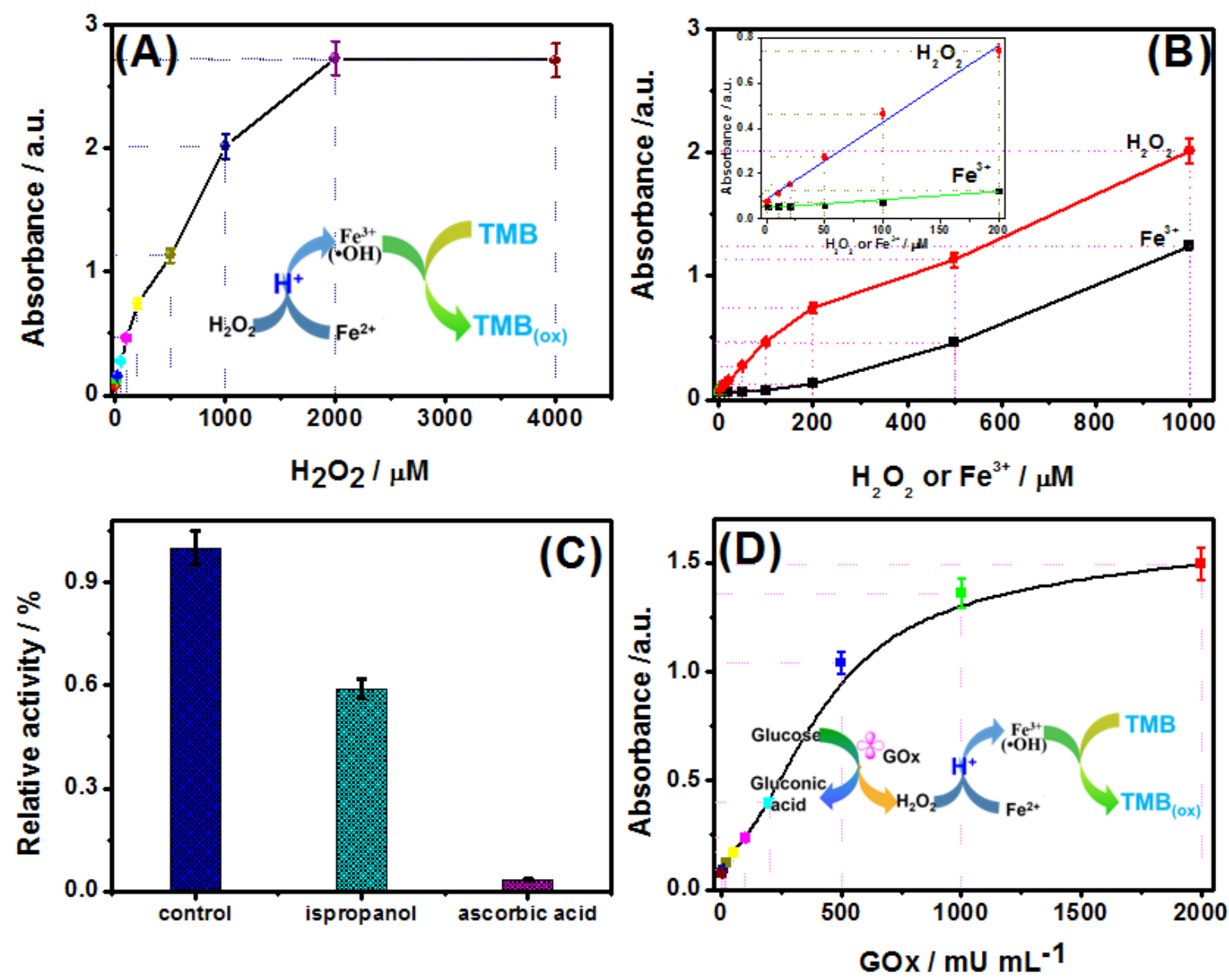

Fig. 4. (A) Absorbance of the TMB-iron(II)- $\mathrm{H}_{2} \mathrm{O}_{2}$ system toward $\mathrm{H}_{2} \mathrm{O}_{2}$ standards, (B) comparison of the TMB-iron(II)- $\mathrm{H}_{2} \mathrm{O}_{2}$ system toward different-concentration $\mathrm{H}_{2} \mathrm{O}_{2}$ standards and TMB-iron(III) system toward different-concentration iron(III) standards in the absorbance (Inset: the corresponding linear plots) (Note: 1.0 $\mathrm{mM}$ TMB and $8.0 \mathrm{mM}$ iron(II) used in these cases; Incubation time: $30 \mathrm{~min}$; Incubation temperature: $25 \pm$ $\left.1.0^{\circ} \mathrm{C}\right),(\mathrm{C})$ the absorbance in the presence of different radical scavengers, and (D) catalytic reactivity of GOx with different concentrations in the TMB-iron(II) system.

\subsection{Analytical performance of Fenton reaction-based colorimetric immunoassay}

Scheme 1 gives the fabrication process of the colorimetric immunoassay for the detection of BTB (used as a model). The assay was carried out on the BTB-MB by using mAb-AuNP-GOx as the signal-generation tag with a competitive-type assay format. In the presence of target BTB, the analyte competed with the immobilized BTB-BSA on the magnetic bead for the labeled anti-BTB antibody on the AuNP. Accompanying the immunocomplex, the carried GOx oxidized glucose into gluconic acid and $\mathrm{H}_{2} \mathrm{O}_{2}$, and the latter could occur Fenton reaction with iron(II) under acidic condition, which could make iron(III)/• $\mathrm{OH}$ oxidize TMB to TMB $\mathrm{Tx}_{\mathrm{ox}}$ thus resulting 
in the change of the absorbance [Note: The calibration curve was prepared by spiking brevetoxin B standards into the Musculista senhousia matrix, and the sample preparation and extraction procedure were described in detail in our previous work (Lai et al., 2015)]. As shown from Fig. $5 \mathrm{~A}$, the absorbance decreased with the increasing BTB concentration in the sample. A good linear dependence between the absorbance (a.u.) and BTB level (ng kg-1) could be acquired in the dynamic range from 0.1 to $150 \mathrm{ng} \mathrm{kg}^{-1}$. The linear regression equation could be fitted to $y=$ $-0.0067 \times C_{[\mathrm{BTB}]}+1.1039\left(\mathrm{ng} \mathrm{kg}^{-1}, R^{2}=0.9992, n=18\right)$. The detection limit (LOD) could be estimated to $76 \pm 0.4 \mathrm{pg} \mathrm{kg}^{-1}$ (ppt) (Note: The range refers to the standard error of the mean) at a signal-to-noise ratio of $3 \delta$ (where $\delta$ is the standard deviation of a blank solution, $n=11$ ) (Fig. 5B). Obviously, the LOD of our strategy was even lower than those of cardiomyocyte-based

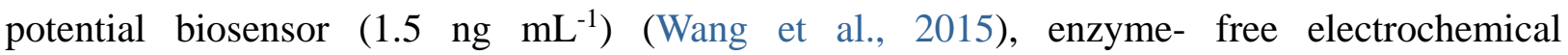
immunoassay (5 $\mathrm{pg} \mathrm{mL}^{-1}$ ) (Lin et al., 2015b), aptamer-based competitive electrochemical biosensor (106 pg mL $\mathrm{mL}^{-1}$ ) (Eissa et al., 2015), Ag(I)-TMB-based colorimetric immunoassay (0.1 ng $\mathrm{kg}^{-1}$ ) (Lai et al., 2015), hollow gold nanosphere-based immunodipstick (0.1 ng mL ${ }^{-1}$ ) (Zhang et al., 2014), homogenous electrochemical immunoassay (6 pg mL $\mathrm{mL}^{-1}$ ) (Zhang et al., 2013), displacement-type quartz crystal microbalance immunoassay (1.0 pg mL ${ }^{-1}$ ) (Tang et al., 2013), capillary electrophoresis-based immunoassay $\left(0.1 \mathrm{ng} \mathrm{mL}^{-1}\right)$ (Zhang and Zhang, 2013), glucose meter-based assay (0.1 $\left.\mathrm{ng} \mathrm{mL}^{-1}\right)$ (Gao et al., 2014b) and commercialized BTB ELISA kit from Abraxis LLC Inc. $\left(50 \mathrm{ng} \mathrm{kg}^{-1}\right)$. Due to the legal limit of brevetoxin $(\leq 80 \mu \mathrm{g}$ of toxin per $100 \mathrm{~g}$ of shellfish tissue) (Hunt et al., 1979; Trainer et al., 1991), the Fenton reaction-based colorimetric immunoassay could completely meet the need of BTB monitoring in seafood.

Next, we investigated the precision of the as-prepared BTB-MB and mAb-AuNP-GOx by monitoring 3 BTB concentrations including 0.5 , 50 and $100 \mathrm{ng} \mathrm{kg}^{-1}$, respectively. The relative standard deviations $(\mathrm{RSD})$ were 7.8, 9.9 and $8.3 \%(n=3)$ for the above-mentioned target BTB, respectively. Therefore, the reproducibility and precision of Fenton reaction-based colorimetric immunoassay were acceptable.

Further, the specificity of Fenton reaction-based colorimetric immunoassay was also studied by spiking brevetoxin A (BTA, $\left.50 \mathrm{ng} \mathrm{kg}{ }^{-1}\right)$, BTB $\left(50 \mathrm{ng} \mathrm{kg}^{-1}\right)$, brevetoxin C (BTC, $\left.50 \mathrm{ng} \mathrm{kg}^{-1}\right)$, okadaic acid (OA, $50 \mathrm{ng} \mathrm{kg}^{-1}$ ), saxitoxin acetate (STA, $50 \mathrm{ng} \mathrm{kg}^{-1}$ ) and dinophysistoxins (DTX, $50 \mathrm{ng} \mathrm{kg}^{-1}$ ) into blank musculista senhousia matrix. As shown from Fig. S3, the BTB-MB and 
mAb-AuNP-GOx displayed a high cross-reactivity toward BTA and BTC, whereas no false compliant results were achieved for OA, STA and DTX. The reason for the false positive results might be the fact that BTA and BTC had a similar chemical structure with BTB.
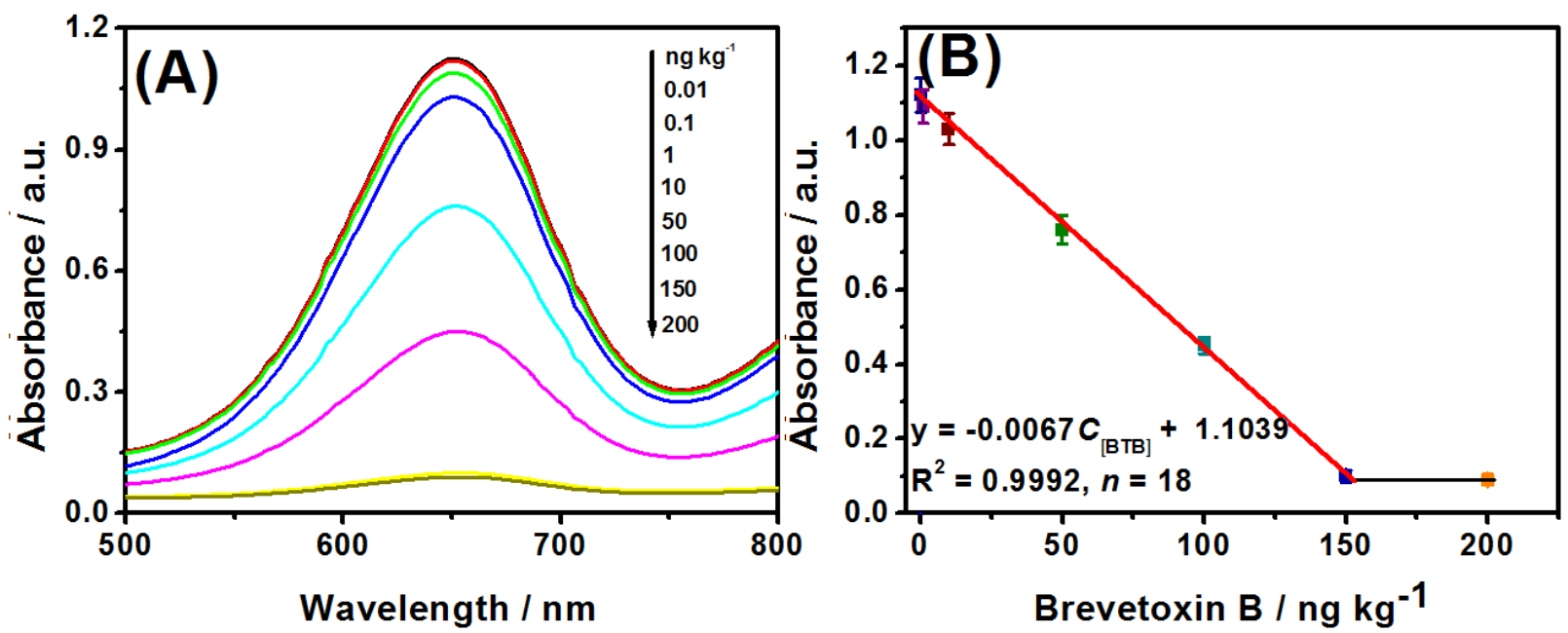

Fig. 5. (A) Absorbance and (B) calibration plots of Fenton reaction-based colorimetric immunoassay toward different-concentration BTB standards.

\subsection{Monitoring of real seafood samples}

The feasibility of Fenton reaction-based colorimetric immunoassay to evaluate brevetoxin B levels in the complex matrix was monitored. Initially we spiked BTB standards at a random concentration into blank musculista senhousia homogenate, followed by centrifugation and extraction, as described in our previous work (Lai et al., 2015). Finally, these samples were assayed by Fenton reaction-based colorimetric immunoassay and commercialized Abraxis BTB ELISA kit (Abraxis LLC, Warminster, USA), respectively. The BTB content in these samples obtained by Fenton reaction-based colorimetric immunoassay was calculated according to the above-fitted regression equation $\left(y=-0.0067 \times C_{[\mathrm{BTB}]}+1.1039\right)$. The results are listed in Table S1. As seen from this table, all RSD values were lower than $10.5 \%$. Moreover, the slope and intercept of the regression equation between two methods $(y=0.9512 x+4.1805)$ were close to ideal ' 1 ' and ' 0 ', respectively, indicating that two methods had a good correlation for detection of target BTB in the real samples.

\subsection{Analysis of real sample by agarose gel-based test kit}


To facilitate the detection of BTB, a portable test kit for the visual detection of BTB was designed as a proof of concept by utilizing agarose gel as visual detection platform. Hydrogel, possessing negligible background color and fluorescence emission, large loading capacity, and controllable shape, is particularly suitable for the visual detection platform. All the components (i.e. polypropylene microcentrifuge tubes, agarose, iron(II), TMB and water) in the test kit are not expensive, and the fabrication procedure is performed under the ambient conditions. The portable test kit was applied to evaluate BTB in the seafood samples. The results are shown in Fig. S4. The colors of the hydrogel turned from dark blue (blank) to pale blue $(1.0-100 \mathrm{ng}$ $\mathrm{kg}^{-1}$ ). Therefore, the portable test kit was preliminarily applicable for the instrument-free visual detection of BTB in real seafood samples.

\section{Conclusions}

In summary, we for the first time systematically demonstrate the unconventional application of Fenton reaction in the conventional colorimetric immunoassay by coupling with the classical iron(II)- $\mathrm{H}_{2} \mathrm{O}_{2}-\mathrm{TMB}$ system. During the signal-transduction process, enzyme-catalyzed product $\left(\mathrm{H}_{2} \mathrm{O}_{2}\right)$ triggered Fenton reaction with iron(II), thus resulting in the development of the visible color and the change in the absorbance. Compared with our previous report (Lai et al., 2015) (i.e., one-molar $\mathrm{H}_{2} \mathrm{O}_{2}$ could cause chemical conversion of one-molar sulfite to sulfate, $1: 1$ ), one-molar $\mathrm{H}_{2} \mathrm{O}_{2}$ in this work could convert one-molar iron(II) into one-molar iron(III) with one-molar $\bullet \mathrm{OH}($ i.e., $1: 2$ ) for the visible development. Nevertheless, only one disadvantage of the developed system is to result in a similar LOD between two methods $\left(0.076 \mathrm{ng} \mathrm{kg}^{-1}\right.$ vs. 0.1 $\mathrm{ng} \mathrm{kg}{ }^{-1}$ ). Therefore, future work should focus on the optimization of experimental conditions for the sensitivity improvement. Although the present system mainly focuses on target BTB, it can be easily extend to determine other small-molecular biotoxins or biomarkers. Importantly, the agarose hydrogel-based test kit by coupling with Fenton reaction does not require sophisticated instrumentations, and is suitable for high-throughput biomedical sensing and application for other areas.

\section{Acknowledgements}


This work was financially supported by the National Natural Science Foundation of China (Grant nos.: 41176079 and 21475025), the National Science Foundation of Fujian Province (Grant no.: 2014J07001), and the Program for Changjiang Scholars and Innovative Research Team in University (Grant no.: IRT15R11).

\section{References}

Eissa, S., Siaj, M., Zourob, M., 2015. Biosens. Bioelectron. 69, 148-154.

Gao, Z., Deng, K., Wang, X., Miró, M., Tang, D., 2014a. ACS Appl. Mater. Interfaces 6, 18243-18250.

Gao, Z.; Tang, D.; Xu, M.; Chen, G.; Yang, H. 2014b. Chem. Commun. 50, 6256-6258.

Gao, Z.; Xu, M.; Hou, L.; Chen, G.; Tang, D. 2013. Anal. Chem. 85, 6945-6952.

Garden, S., Strachan, N., 2001. Anal. Chim. Acta. 44, 187-191.

González-Fuenzalida, R., Moliner-Martínez, Y., González-Béjar, M., Molons-Legua, C., Verdú-Andres, J., Pérez-Prieto, J., Campins-Falcó, P., 2013. Anal. Chem. 85, 10013-10016.

Hunt, D., Tufts, N, 1979, Elsevier Press, New York 489-492.

Jiang, W., Wang, Z., Beier, R., Jiang, H., Wu, Y., Shen, J., 2013. Anal. Chem. 85, 1995-1999.

Jv, Y., Li, B., Cao, R., 2010. Chem. Commun. 46, 8017-8019.

Korde, A., Pandey, U., Banerjee, S., Sarma, H., Hajare, S., Venkatesh, M., Sharma, A., Pillai, N., 2003. J. Agric. Food. Chem. 51, 843-846.

Lai, W., Tang, D., Zhuang, J., Chen, G., Yang, H., 2014. Anal. Chem. 86, 5061-5068.

Lai, W., Zhuang, J., Tang, D., 2015. J. Agric. Food. Chem. 63, 1982-1989.

Li, Y., Wang, Z., Beier, R., Shen, J., Smet, D., Saeger, S., Zhang, S., 2011. J. Agric. Food. Chem. 59, $3411-3453$

Li, Y., Luo, X., Yang, S., Cao, X., Wang, Z., Shi, W., Zhang, S, 2014. J. Agric. Food. Chem. 62, 1492-1497.

Lin, Y., Zhou, Q., Lin, Y., Tang, D., Niessner, R., Knopp, D., 2015a. Anal. Chem. 87, 8531-8540.

Lin, Y., Zhou, Q., Lin, Y., Lu, M., Tang, D., 2015b. Anal. Chim. Acta 887, 67-74.

Liu, M., Zhao, H., Chen, S., Yu, H., Quan, X., 2012a. ACS Nano 6, 3142-3151.

Liu, S., Tian, J., Wang, L., Su, X., 2012b. Sens. Actu. B 165, 44-47.

Lu, C., Liu, X., Li, Y., Yu, F., Tang, L., Hu, Y., Ying, Y., 2015. ACS Appl. Mater. Interfaces 7, 15395-15402.

Lyu, L., Zhang, L., Wang, Q., Nie, Y., Hu, C., 2015. Environ. Sci. Technol. 49, 8639-8647.

Nguyen, D., Zhang, Z., Doherty, W., 2015. J. Agric. Food. Chem. 63, 1582-1592.

Sedlak, D., Andren, A., 1991. Environ. Sci. Technol. 25, 777-782.

Tang, D., Su, B., Tang, J., Ren, J., Chen, G., 2010. Anal. Chem. 82, 1572-1534.

Tang, D., Zhang, B., Tang, J., Hou, L., Chen, G., 2013. Anal. Chem. 85, 6958-6966.

Tang, J., Tang, D., Niessner, R., Chen, G., Knopp, D., 2011. Anal. Chem. 83, 5407-5414.

Trainer, V., Baden, D., 1991. Toxicon 29, 1387-1394.

Walling, C., 1975. Acc. Chem. Res. 8, 125-131. 
Walling, C., Amarnath, K., 1982. J. Am. Chem. Soc. 104, 1185-1189.

Wan, Y., Qi, P., Zhang, D., Wu, J., Wang, Y., 2012. Biosens. Bioelectron. 33, 69-74.

Wang, Q., Fang, J., Cao, D., Li, H., Su, K., Hu, N., Wang, P., 2015. Biosens. Bioelectron. 72, 10-17.

Wang, Y., Yan, Y., Ji, W., Wang, H., Zou, Q., Sun, J., 2013. J. Agric. Food. Chem. 61, 4250-4256.

Xianyu, Y., Wang, Z., Jiang, X., 2014. ACS Nano 8, 12741-12747.

Yu, F., Zhou, M., Zhou, L., Peng, R., 2014. Environ. Sci. Technol. Lett. 1, 320-324.

Zazo, J., Casas, J., Mohedano, A., Gilarranz, M., Rodríguez, J., 2005. Environ. Sci. Technol. 39, 9295-9302.

Zhang, B., Hou, L., Tang, D., Liu, B., Li, J., Chen, G., 2012. J. Agric. Food. Chem. 60, 8974-8982.

Zhang, B., Liu, B., Liao, J., Chen, G., Tang, D., 2013. Anal. Chem. 85, 9245-9252.

Zhang, K., Wu, J., Li, Y., Wu, Y., Huang, T., Tang, D., 2014. Microchim. Acta 181, 1447-1454.

Zhang, Q., Zhao, B., Yan, J., Song, S., Min, R., Fan, C., 2011. Anal. Chem. 83, 9191-9196.

Zhang, X., Zhang, Z., 2013. J. Chromatogr. Sci 51, 107-111.

Zhou, C., Zhao, J., Pang, D., Zhang, Z., 2014. Anal. Chem. 86, 2752-2759.

Zhou, G., Liu, Y., Luo, M., Xu, Q., Ji, X., He, Z., 2012. ACS Appl. Mater. Interfaces 4, 5010-5015. 